\title{
The Necrotic Venom of the Brown Recluse Spider Induces Dysregulated Endothelial Cell-dependent Neutrophil Activation

\author{
Differential Induction of GM-CSF, IL-8, and E-Selectin Expression
}

\author{
Kamala D. Patel, ${ }^{\ddagger}$ Vijayanand Modur, ${ }^{\ddagger}$ Guy A. Zimmerman, ${ }^{\star}$ Stephen M. Prescott, ${ }^{\star \ddagger}$ and Thomas M. McIntyre* \\ Nora Eccles Harrison Cardiovascular Research and Training Institute, the Eccles Program in Human Molecular Biology and Genetics, \\ and the Departments of * Internal Medicine and ${ }^{\ddagger}$ Biochemistry, University of Utah, Salt Lake City, Utah 84112
}

\begin{abstract}
Brown recluse spider (Loxosceles reclusa) venom induces severe dermonecrotic lesions. The mechanism for this is unknown but presents an interesting paradox: necrosis is completely dependent on the victim's neutrophils, yet neutrophils are not activated by the venom. We show Loxosceles venom is a potent, but disjointed, endothelial cell agonist. It weakly induced E-selectin expression, but not intercellular adhesion molecule-1 or IL-6 expression, yet significantly stimulated release of $\mathrm{IL-8}$ and large amounts of GM-CSF by $4 \mathrm{~h}$. In contrast, TNF strongly induced all of these, except for GM-CSF. PMN bound to E-selectin on venom-activated endothelial cells, apparently via counterreceptors different from those that bind E-selectin on TNF $\alpha$-activated monolayers. Notably, PMN bound venom-activated monolayers only at intercellular junctions, did not polarize, and completely failed to migrate beneath the monolayer. Despite this, bound PMN demonstrated increased intracellular $\mathrm{Ca}^{2+}$ levels and secreted primary and secondary granule markers. The latter event was suppressed by sulfones used to treat envenomation. We have defined a new endothelial cell agonist, Loxosceles venom, that differentially stimulates the inflammatory response of endothelial cells. This, in turn, leads to a dysregulated PMN response where adhesion and degranulation are completely dissociated from shape change and transmigration. (J. Clin. Invest. 1994. 94:631-642.) Key words: E-selectin • interleukin-8 • granulocyte macrophage colony-stimulating factor $\bullet$ spider venom $\bullet$ endothelium
\end{abstract}

\section{Introduction}

Envenomation by the brown recluse spider (Loxosceles reclusa), its desert counterpart (Loxosceles deserta) $(1,2)$, or the South American Loxosceles Laeta (1) can result in an impressive dermonecrotic lesion. This progresses from an acute local inflammatory reaction to a black eschar, where sloughing of the necrotic tissue leaves a draining, well demarcated ulcer (3). These lesions are remarkable considering that these spiders emit only a few tenths of a microliter of venom (4). The mechanism by which the venom causes necrotic lesions is currently un-

Address correspondence to Dr. Thomas M. McIntyre, CVRTI, Building 500, University of Utah, Salt Lake City, UT 84112.

Received for publication 3 June 1993 and in revised form 31 March 1994.

J. Clin. Invest.

(C) The American Society for Clinical Investigation, Inc. $0021-9738 / 94 / 08 / 0631 / 12 \$ 2.00$

Volume 94, August 1994, 631-642 known. The PMN (neutrophil) might be expected to be the central target of the venom because depletion of PMN with a single dose of nitrogen mustard delays hemorrhage, edema, and necrosis until the pool of circulating neutrophils is reestablished (5). This key observation shows that PMN are likely the proximal cause of the tissue destruction associated with the intense inflammatory reaction after envenomation. However, human neutrophils are not themselves activated by the venom ex vivo and, in fact, are actually inhibited by it $(6,7)$. This apparent paradox may be resolved by the observation (8) that the first ultrastructural change after envenomation is selective damage to vascular endothelium, while at the level of light microscopy it is adhesion of neutrophils to the capillary wall (9). This suggests that an essential component of this inflammatory reaction may be activation of vascular endothelium, with subsequent sequestration and activation of passing neutrophils by the perturbed endothelial cells.

The initial step in leukocyte emigration from the blood stream is their interaction with the endothelium. This may occur either by directly activating neutrophils, which functionally upregulates their CD11/CD18 adhesive glycoprotein complex, or by activating endothelial cells to express neutrophil tethering and activating molecules (10). Adhesion by the activated CD11/ CD18 integrins is sensitive to the shear (11) of flowing blood and in the absence of stasis is not likely to be the initial event in leukocyte interaction with the vascular wall. In contrast, endothelial cell-dependent adhesion, by virtue of the adhesion molecules presented by activated endothelial cells, is resistant to this. There is a general paradigm by which activated endothelial cells bind neutrophils: two inflammatory processes use different molecules to accomplish similar functions (10). Agonists like thrombin and histamine within minutes induce the translocation of P-selectin from intracellular granules, Weibel-Palade bodies, to the apical endothelial cell surface. Surface P-selectin acts to tether neutrophils to the endothelial cells by binding to a sialylated counterreceptor on neutrophils. Simultaneously, endothelial cells synthesize platelet-activating factor and translocate it to their plasma membrane, where it can activate the tethered neutrophils through a specific receptor. This juxtacrine stimulation ensures that only adherent neutrophils are stimulated to extravasate. Similarly, endothelial cells exposed to TNF $\alpha$, IL-1, or endotoxin begin to synthesize and then express a related tethering molecule, E-selectin $(10,12)$. This process occurs over a period of hours as neither E-selectin nor its mRNA is detectable in unactivated endothelial cells. Tethered PMN are activated by cytokine-induced endothelial cells and, although the nature of the neutrophil stimulatory molecule(s) in this setting is not completely defined, cytokine-activated endothelial cells also begin to synthesize and release the PMN agonist IL-8.

Here we tested the hypotheses that Loxosceles venom is an endothelial cell agonist and that these activated endothelial cells in turn activate PMN. We exposed primary cultures of human 
umbilical vein endothelial cells to minute amounts of Loxosceles venom and found that by $4 \mathrm{~h}$ treated monolayers bound and activated human neutrophils. However, the venom differentially induced endothelial cell inflammatory events. We found a weak, but functional, expression of E-selectin compared with TNF $\alpha$-activated monolayers, a complete lack of IL-6 induction, coupled with a strong IL-8 and GM-CSF response. The synthesis and release of GM-CSF were particularly noteworthy as this cytokine is only produced at later times after $\mathrm{TNF} \alpha$ activation. However, more striking was the PMN response to this dysregulated endothelial cell activation. PMN adhered only to the junctions of venom-activated endothelial cells, and they did not alter their morphology to a polarized form nor did they migrate beneath the monolayer. Despite this lack of motile responses, adherent PMN released contents from both primary and secondary granules. Therefore, we have defined a new endothelial cell agonist, but find that it differentially induces inflammatory responses of endothelial cells: it dissects events leading to PMN shape change and chemotaxis from those that result in degranulation. This dysregulated inflammatory response may account for the tissue destruction associated with envenomation by Loxosceles spiders.

\section{Methods}

Materiäls. Venom, collected from the fangs of Loxosceles deserta by electrical stimulation of the spiders (to prevent contamination with gastric contents), was obtained from Spider Pharm (Feasterville, PA) [(215) 355-8295]. Venom was stored as small aliquots at $-80^{\circ} \mathrm{C}$; it was thawed, diluted 100 -fold with HBSS containing $0.5 \%$ human serum albumin $(\mathrm{HBSS} / \mathrm{A})^{\prime}$, and centrifuged in a microfuge to remove precipitated material. A fresh lot was prepared weekly as thawed venom loses activity over a period of several days and is inactivated by a single round of freeze/thaw after this dilution. Recombinant human TNF $\alpha$ was provided by Genentech Inc. (South San Francisco, CA). HL60 cells were obtained from American Type Culture Collection (Rockville, MD) and cultured in RPMI 1640 as recommended. HBSS and M199 were from Whittaker Bioproducts (Walkersville, MD), and human serum albumin (25\%) was from Miles Laboratories Inc. (Elkhart, IN). Monoclonal antibodies P6E2 and L1.4 were, respectively, donated by James Paulson (Cytel, San Diego, CA) and Thomas Tedder (Harvard University, Cambridge, MA). Monoclonal antibodies 3B7, 7H5, and 8E4 were the gifts of Barry Wolitzky (Hoffman-La Roche, Nutley, NJ). mAb 60.3 and IB4 were supplied by Patrick Beatty (University of Utah, Salt Lake City, UT) and Samuel D. Wright (The Rockefeller University, New York). Robert Rothlein (Boehringer Ingelheim Ltd., Ridgefield, CT) supplied RR1.4, $\mathrm{mAb} 13$ was originally from Steve Akiyama (National Institutes of Health), and mAb 18E3D was kindly supplied by W. Michael Gallitin (ICOS Corp., Seattle, WA). The blocking anti-PECAM-1 (CD31) mAb was a generous gift from William A. Muller (The Rockefeller University, New York). Rodger McEver (Oklahoma Medical Research Foundation, Oklahoma City, OK) provided G1 mAb that blocks PMN adhesion to P-selectin, while BBA2 and BBA4 were purchased from British Biotechnology (Oxford, U.K.). Polyclonal rabbit anti-human IL-8 and recombinant human IL-8 were from Research \& Diagnostic System (Minneapolis, MN), while mouse anti-human GM-CSF, polyclonal rabbit anti-human GM-CSF, and recombinant human GM-CSF were from Genzyme Corp. (Cambridge, MA). Endogen Inc. (Boston, MA) supplied rabbit anti-human IL-6 polyclonal antibody, and Biosource International (Camarillo, CA) supplied recombinant human IL-6. INDO-1 AM was from Molecular Probes (Eugene, OR). Rp-cAMPS triethylamine

1. Abbreviations used in this paper: BRSV, brown recluse spider venom; HBSS/A, HBSS containing $0.5 \%$ HSA; HUVEC, human umbilical vein endothelial cells; ICAM-1, intercellular adhesion molecule-1. salt was from Research Biochemicals International (Natick, OR); other reagents were from Sigma Immunochemicals (St. Louis, MO).

Cells, manipulations, and imaging. Human umbilical vein endothelial cells (HUVEC) were cultured in 24-mm multiwell plates (Costar Corp., Cambridge, MA) as described (13). Only monolayers of primary cultures that were tightly confluent were used for these studies. Neutrophils were isolated from human blood and labeled with ${ }^{111}$ In-oxine as described (13). Endothelial cells were treated with the stated agonist in HBSS/A for the specified period of time and washed with HBSS, and the percentage of "II In-neutrophils that tightly adhered in 5 min was quantified as described (14). HL60 cell adhesion and a parallel PMN control were quantitated by counting the number of adherent leukocytes in five random high-power fields. When the effect of antibodies on PMN-endothelial cell interactions was examined, the appropriate cell was preincubated with $10 \mu \mathrm{g} / \mathrm{ml}$ of the $\mathrm{mAb}$ for $30 \mathrm{~min}$, and the adhesion assay was performed in the presence of this concentration of antibody. This standard concentration of antibody may not have been optimal for all antibodies, but the limiting amount of some antibodies precluded extensive characterization of each. A positive control for antibody effectiveness was included in each experiment. Potential effects mediated by endotoxin were assessed using polymyxin B to sequester it: $10 \mu \mathrm{g}$ of polymyxin B was added to buffer, appropriately diluted venom, or 20 $\mathrm{ng} / \mathrm{ml}$ endotoxin as a control. The ability of venom to directly promote neutrophil adhesion via CD11/CD18 functional upregulation was determined by measuring adhesion to a gelatin matrix as described (15). Protein synthesis was inhibited in endothelial cell monolayers by incubating the monolayers with $5 \mu \mathrm{g} / \mathrm{ml}$ actinomycin D or $5 \mu \mathrm{M}$ emetine for $30 \mathrm{~min}$ at $37^{\circ} \mathrm{C}$ before addition of the experimental agent. These monolayers, in the continued presence of actinomycin D or emetine, were incubated for $4 \mathrm{~h}$ before the effect of the inhibitors on adhesion was determined. The effect of lactose-1-phosphate (16) or chymotrypsin (17) on neutrophil adhesion was determined as described. Adhesion of neutrophils preactivated for 15 min with $1 \mu \mathrm{M}$ FMLP or $1 \mu \mathrm{M}$ PMA in calcium- and magnesium-free HBSS was performed by washing the activated neutrophils, resuspending them in HBSS/A, and performing the adhesion assay at $64 \mathrm{rpm}$ (as shear blocks CD18-mediated adhesion) as described (18). Cells were visualized by capturing the microscopic image with a video camera onto videotape. A framegrabber and NIH Image 1.47 were used to obtain a single image. Confocal microscopy with E-selectin mAb P6E2 was performed as described (19). PMN were labeled with INDO-1 AM, and $\mathrm{Ca}^{2+}$-enhanced fluorescence was quantitated in a custom microscopic well as described $(20,21)$. All adhesion values are reported as the mean and range of duplicate values and are representative of at least two experiments.

Analytical assays. Degranulation of PMN adhering to endothelial cell monolayers was measured by release of lactoferrin and elastase during a 2-h coincubation: these proteins were assayed by sandwich ELISA as described (22). GM-CSF, IL-6, and IL-8 were quantitated by sandwich ELISA. The capture antibody was mouse anti-human GMCSF, and the second antibody was polyclonal rabbit anti-human GMCSF. Horseradish peroxidase-conjugated donkey anti-rabbit IgG $\mathrm{F}_{\mathrm{ab}}$ ' fragments (Amersham Corp., Arlington Heights, IL) were used for detection in this assay, and recombinant human GM-CSF was used to create the standard curve. IL- 8 or IL- 6 was determined with polyclonal rabbit anti-human antibody; detection used biotinylated rabbit antihuman IL-8 or IL-6 and avidin-conjugated horseradish peroxidase. When the effect of dapsone (or other sulfones) on degranulation was examined, it was present at the stated concentration during the neutrophil-endothelial cell coincubation. FACS ${ }^{\circledR}$ analysis of PMN L-selectin was performed with fluorescein-conjugated Leu-8 (Becton Dickinson, San Jose, CA). E-selectin on the surface of control and activated endothelial cell monolayers was visualized by confocal microscopy with a fluorescent second antibody as described (23). Surface expression of Eselectin or intercellular adhesion molecule-1 (ICAM-1) was quantitated by removing treated or control endothelial cells by swirling them for 3 min at $24^{\circ} \mathrm{C}$ on an orbital shaker at $200 \mathrm{rpm}$ in the presence of $1 \times$ trypsin-EDTA (GIBCO BRL, Gaithersburg, MD). A few persistently adherent cells were removed by gently repipetting the contents of the culture dish. The cells were washed twice in $50 \%$ horse serum diluted 

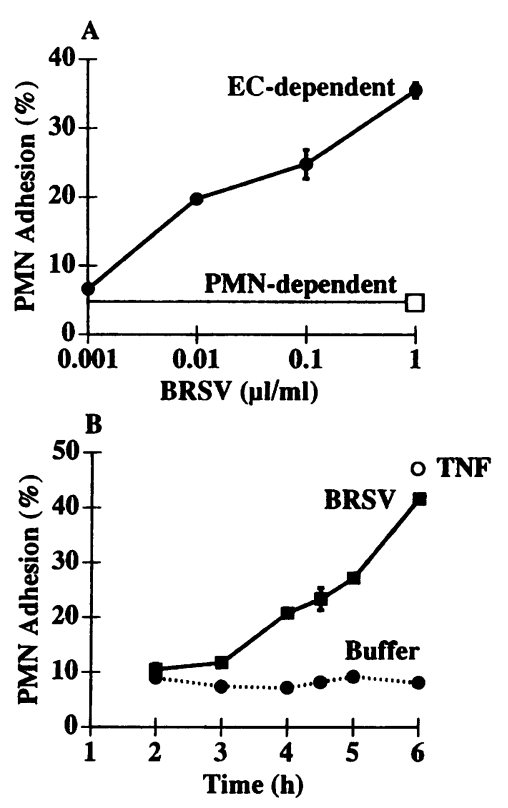

Figure 1. PMN adherence to Loxosceles venom-activated endothelial cells is concentration and time dependent. $(A)$ Endothelial cell-dependent adhesion was measured by treating primary cultures of endothelial cells from HUVEC with the stated concentration of Loxosceles venom (brown recluse spider venom, $B R S V$ ) at $37^{\circ} \mathrm{C}$ for $4 \mathrm{~h}$. This incubation buffer was removed, and freshly isolated quiescent human neutrophils $\left(2.25 \times 10^{6}\right.$ in $0.5 \mathrm{ml} \mathrm{HBSS} / \mathrm{A}$ ) were added for a 5-min incubation at $37^{\circ} \mathrm{C}$. Unbound and loosely adherent neutrophils were re-

moved, and adherent neutrophils were quantitated as described in Methods. PMN-dependent adhesion was determined by treating PMN with $1 \mu \mathrm{l} / \mathrm{ml}$ of Loxosceles venom for $5 \mathrm{~min}$ and quantitating their adhesion to a gelatin matrix as described (15). (B) Endothelial monolayers were treated at $37^{\circ} \mathrm{C}$ with buffer, $250 \mathrm{U} / \mathrm{ml} \mathrm{TNF} \alpha$, or $0.1 \mu \mathrm{l} / \mathrm{ml}$ of Loxosceles venom for the stated time before neutrophil adhesion was determined. Values shown represent the mean and range of duplicate points. These results are typical of seven $(A)$ and five $(B)$ experiments.

in PBS and stained with anti-E-selectin (P6E2) or ICAM-1 (18E3D) monoclonal antibody in this buffer. Staining with FITC-conjugated goat anti-mouse (Sigma Immunochemicals), also in 50\% horse serum, was followed by fixation in $0.5 \%$ formaldehyde. Viability of recovered unfixed cells was examined in parallel using propidium iodide stain; this population was used to gate FITC-labeled cells. Material for Western blots was collected by solubilizing monolayers with boiling sample buffer containing $10 \%$ SDS but not $\beta$-mercaptoethanol. Proteins were electrophoretically separated under nonreducting conditions on $7.5 \%$ SDS polyacrylamide gels and then transferred to Immobilon (Millipore) membrane. The membrane was blocked with $5 \%$ nonfat milk and probed with the anti-E-selectin monoclonal antibody BBA-8 (British Biotechnology). This was developed with horseradish peroxidase-conjugated polyclonal goat anti-mouse in the presence of $100 \mu \mathrm{g} / \mathrm{ml}$ nonimmune rabbit IgG. Staining was detected with ECL (Amersham Corp.) and Kodak XAR-5 film according to the manufacturer's instructions. NIH Image 1.47 was used to estimate the density of the scanned bands. Reverse transcription of cDNA from endothelial cell monolayers grown in 0.8-cm wells and PCR ( 25 cycles) quantitation of E-selectin message, using glyceraldehyde-3-phosphate dehydrogenase as a control, were performed using manufacturer's protocols under quantitative conditions (24). The forward primer E1111F was 5' ACT TCA CCT GTG AGG AAG GCT TC-3', while the reverse primer E1682R was 5' GCA GAG CCA TTG AGC GTC CAT CCT-3' (25).

\section{Results}

Loxosceles venom activates endothelial cells. We exposed primary cultures of endothelial cells to varying amounts of Loxosceles venom for $4 \mathrm{~h}$, washed them, and then incubated freshly isolated, unactivated PMN with these monolayers. We found that PMN bound to venom-activated endothelial cells and that adhesion was dependent on the amount of venom used (Fig. 1 $A)$. The venom was quite potent, as little as $0.01 \mu \mathrm{l} / \mathrm{ml}$ signifi- cantly enhanced endothelial cell-dependent PMN adhesion. This sensitivity of endothelial cells to the venom is consistent with the ability of a few tenths of a microliter of injected venom to elicit an effect in vivo. Although levels of neutrophil adhesion could be attained that were equivalent to those of cytokineactivated monolayers, the limited supply of venom dictated that the majority of our experiments be performed with submaximal amounts $(0.1 \mu \mathrm{l})$ of venom. We next exposed endothelial cells to the venom for various periods of time, and then examined the ability of unactivated PMN to bind in $5 \mathrm{~min}$ to the treated monolayers. We found (Fig. $1 B$ ) that development of the adhesive surface required at least $2 \mathrm{~h}$ of exposure to venom, while maximal adhesion normally developed after $6 \mathrm{~h}$ of continuous venom exposure. At this time, PMN adhesion nearly equaled that induced by exposure to TNF $\alpha$. Even though adhesion after $4 \mathrm{~h}$ of venom exposure typically was only half that induced by cytokine activation, we used this time in all other experiments to simplify the pattern of adhesion molecules expressed by the cytokine-treated positive controls $(18,26)$. We found (not shown) that venom was sensitive to boiling and that venominduced adhesion was not blocked by polymyxin B at concentrations that effectively block adhesion to monolayers treated with up to $20 \mathrm{ng} / \mathrm{ml}$ Escherichia coli lipopolysaccharide. From this we conclude that endotoxin contamination did not account for the effects of the venom on endothelial cells. The development of an adhesive surface by venom-treated endothelial cells did not require the continued presence of the venom. Removing the venom from the incubation medium after $2 \mathrm{~h}$ and then allowing the incubation to continue for an additional $2 \mathrm{~h}$ resulted in $75 \%$ of the adhesion that developed upon continuous exposure (not shown). Residual venom on the monolayer acting on the added PMN did not account for the adherence we observed because directly incubating PMN with the venom did not induce functional upregulation of their CD11/CD18 integrins (Fig. $1 A$ ). We conclude that in this system the venom is an endothelial cell-specific agonist.

PMN-endothelial cell interaction appears to be selectin mediated. Endothelial cell-dependent adhesion, whether mediated by P-selectin or E-selectin, has several distinguishing characteristics. Our initial approach to defining the relevant adhesion molecule on venom-activated endothelial cells was to determine if the attributes of selectin-mediated adhesion were displayed in this system. We found (Fig. 2) PMN adhesion to venomactivated monolayers to be resistant to shear force, a selectin attribute. We also found that adhesion was inhibited by the chelator EDTA (Fig. 2) and that $\mathrm{Ca}^{2+}$ or $\mathrm{Mg}^{2+}$ partially restored adhesion (not shown). Together, these ions completely overcame the inhibition of adhesion by EDTA. Selectins recognize sialylated carbohydrate ligands on PMN (27). Accordingly, we observed that pretreatment of the PMN with sialidase blocked adhesion to monolayers exposed to Loxosceles venom (Fig. 2), as well as to TNF $\alpha$-treated monolayers, the positive control. The counterligand on PMN that binds to E-selectin is lost by either activation of the PMN before the adhesion assay (28) or by pretreatment with low concentrations of chymotrypsin (17, 29). We found (Fig. 2) that both of these treatments blocked PMN adhesion to venom- and TNF $\alpha$-treated monolayers. These data indicate that PMN adhesion to Loxosceles-exposed endothelial cells is consistent with a selectin being the tethering molecule. To strengthen this inference, we determined if other leukocyte or endothelial cell adhesion molecules had a role in venom-induced adhesion. We found that blocking anti- $\beta 1$ (mAb 13), anti-CD18 (mAb 60.3, IB4), anti-L-selectin (mAb LAM 


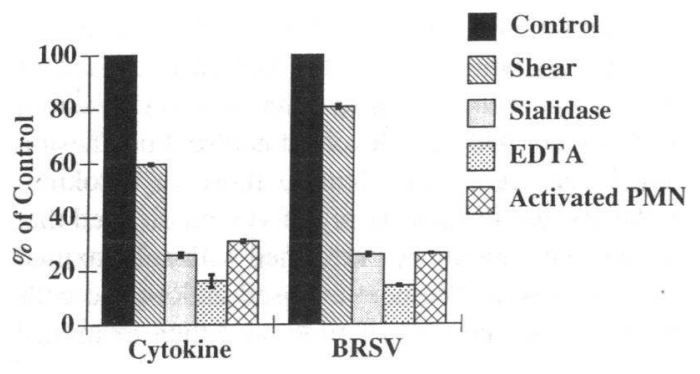

Figure 2. PMN adhesion to Loxosceles venom-activated endothelial cells appears to be mediated by a selectin. Endothelial cell monolayers were treated for $4 \mathrm{~h}$ with HBSS/A alone or with either $250 \mathrm{U} / \mathrm{ml}$ TNF or $0.1 \mu \mathrm{l} \mathrm{BRSV} / \mathrm{ml}$. After the incubation, the monolayers were washed, and PMN adhesion was determined as described in Methods. The neutrophils were either untreated controls or ones that had been activated for $15 \mathrm{~min}$ with $1 \mu \mathrm{g} / \mathrm{ml} \mathrm{f}$-met-leu-phe in $\mathrm{Ca}^{2+}, \mathrm{Mg}^{2+}$-free medium and then resuspended in HBSS/A before addition to the endothelial cells. Adhesion in the presence of $1 \mathrm{mM}$ EDTA or after sialidase treatment of the PMN was as described in Methods. Values shown represent the mean and range of duplicate points and are expressed as a percentage of control adhesion in that experiment. The shear, sialidase, EDTA, and preactivation experiments were performed $14,7,2$, and 5 times, respectively, with equivalent results.

1.4), and anti-ICAM-1 (mAb BBA4, RR1.4) antibodies uniformly failed to block adhesion to venom-activated monolayers. These data indicate that PMN adhesion to Loxosceles-treated endothelial cells is characteristic of a selectin-mediated event: the failure of a blocking L-selectin antibody to affect this interaction implicates P-selectin or E-selectin as the relevant molecule.

E-selectin mediates venom-induced adhesion. We first examined the effect of a monoclonal antibody that inhibits Pselectin function on venom-induced PMN adhesion. We found that $\mathrm{mAb} \mathrm{Gl}$, under conditions where it blocks adhesion to thrombin-activated endothelial cells (30) or to transfected Chinese hamster ovary cells stably expressing human recombinant P-selectin (31), failed to block adhesion after venom exposure (not shown). As P-selectin was not involved in this intercellular interaction, we investigated the ability of Loxosceles venom to induce E-selectin expression. Since E-selectin is not normally present on endothelial cells and must be synthesized de novo in response to agonist stimulation, we determined if protein synthesis was required for adhesion to venom-treated monolayers. We found that treatment of endothelial cells with either transcriptional or translational inhibitors during induction with venom, or TNF $\alpha$, blocked the development of a surface that promoted PMN adhesion (77 and 65\% inhibition to venomtreated monolayers and 62 and $54 \%$ to TNF $\alpha$-treated monolayers by actinomycin $\mathrm{D}$ and emetine, respectively). We next tested whether Loxosceles venom induced expression and accumulation of E-selectin mRNA using a semiquantitative reverse transcriptase-PCR approach. This method is particularly useful here as endothelial cells normally contain no message for Eselectin, so we can follow induction of this message against a nonexistent background. We found (Fig. $3 \mathrm{~A}$ ), as expected, that buffer-treated control cells did not contain detectable levels of message, while cells treated for $3 \mathrm{~h}$ with TNF $\alpha$ contained significant amounts of message. We also found that endothelial cells exposed to Loxosceles venom contained E-selectin message by $3 \mathrm{~h}$ of venom exposure, with enhanced expression at 6 h. However, it was apparent, at least over the initial $6 \mathrm{~h}$ of exposure, that venom was less potent than TNF $\alpha$ as an agonist for induction of E-selectin transcription. We next asked whether this message was translated by quantitating immunoreactive material after electrophoretic separation and probing of the blotted proteins with an anti-E-selectin mAb. This Western blot (Fig. $3 \mathrm{~B}$ ) showed that venom-exposed cells expressed E-selectin, and that it comigrated with E-selectin expressed by cytokine-activated cells. Again, it was apparent that Loxosceles venom was only a weak agonist for E-selectin expression: quantitation of the developed blots showed that venom exposure induced $<10 \%$ of the E-selectin expressed by TNF $\alpha$-treated endothelial cells. This ratio of immunoreactive protein was maintained for at least $8 \mathrm{~h}$ of exposure (not shown), indicating that this difference was not merely due to a slower rate of induction. We then determined if this limited amount of protein was expressed on the cell surface using an anti-E-selectin mAb and a fluorescently labeled second antibody. We found that endothelial cell monolayers exposed to venom, or TNF $\alpha$ as a positive control, visibly expressed E-selectin on their surface (not shown). Confocal microscopy showed that the apical surface of the cells was stained, with only occasional junctional staining, so confluent monolayers properly displayed this protein. Finally, we quantitated E-selectin surface expression by FACS ${ }^{\circledR}$ analysis. We found (Fig. $3 C$ ) that E-selectin expression was significantly above the nonspecific staining of control cells, but was well below the levels expressed by cytokine-stimulated cells. We also determined if Loxosceles venom induced the surface expression of ICAM-1, as this is important in neutrophil adhesion to cytokine-activated endothelial cells. Fig. $3 C$ shows that, where we detected weak E-selectin expression in response to venom exposure, we were unable to detect a significant increase in ICAM-1 surface expression. It is important to note that, for this determination and for the Western blot analysis, the level of neutrophil adhesion to venom-stimulated monolayers was adjusted to that of cytokine-treated monolayers by using three times more venom than we generally used. Together these three independent approaches have demonstrated that Loxosceles venom induces E-selectin expression but is a far less potent agonist than TNF $\alpha$ for this process.

Our next goal was to determine if the E-selectin expressed in response to Loxosceles venom accounted for PMN adhesion to these cells. We examined this issue by determining the effect of a panel of blocking anti-E-selectin monoclonal antibodies on adhesion to venom-activated endothelial cells. We found (Fig. 4) that these antibodies significantly inhibited adhesion to both TNF $\alpha$-activated and venom-activated monolayers; mAb 3B7 and P6E2 were particularly effective and suppressed 70$80 \%$ of PMN adhesion to venom-activated endothelial cells. Three of these monoclonal antibodies have been epitope mapped (32) to a small region of the lectin-binding domain responsible for carbohydrate recognition, indicating that the same critical region of E-selectin is involved in PMN tethering after its induction by either agonist. We also found that PMN adhesion and E-selectin expression in response to venom treatment were prolonged events: PMN adhered to monolayers exposed to venom for $18 \mathrm{~h}$, and this was abolished by E-selectin antibody (not shown). Thus Loxosceles venom stimulates the synthesis and surface expression of a limited amount of Eselectin, yet this underrepresented molecule is the primary agent mediating PMN adhesion to these cells.

Neutrophil adhesion to venom-activated endothelial cells is unusual. Venom-activated endothelial cells express E-selectin, but these monolayers have characteristics that distinguish their 

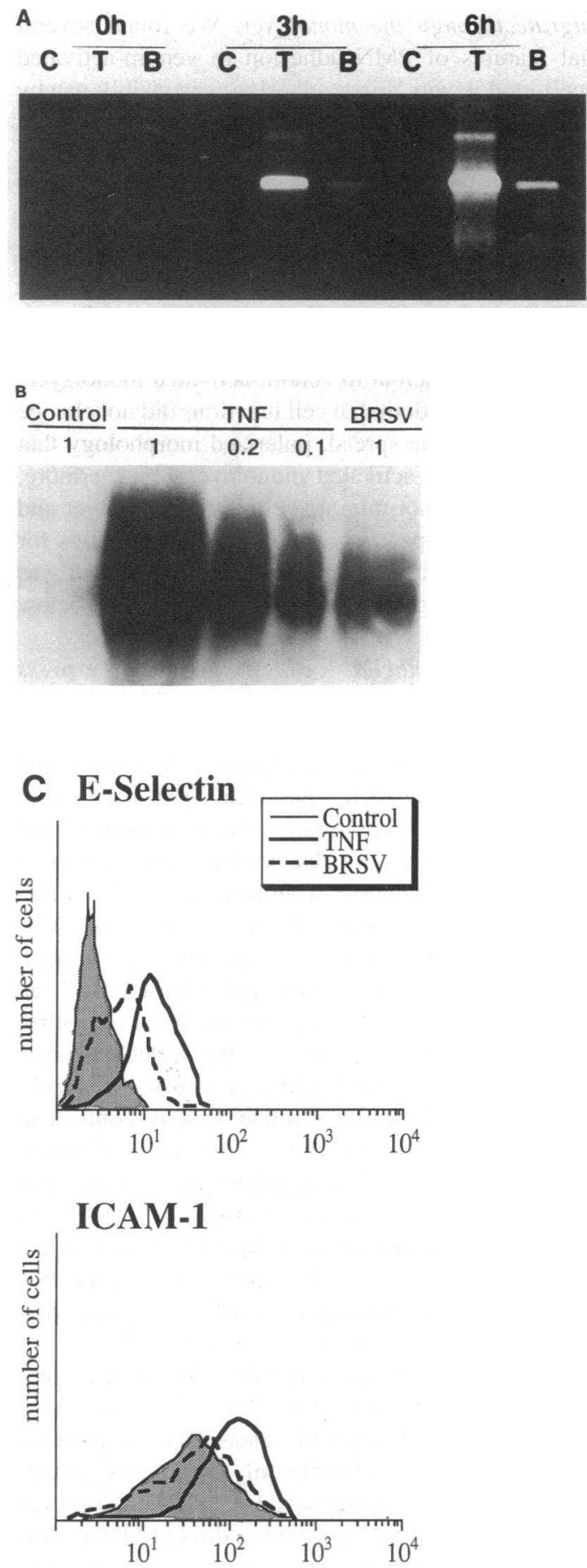

Figure 3. E-selectin is weakly expressed by Loxosceles venom-activated endothelial cells. $(A)$ Semiquantitative PCR quantitation of Eselectin message. Endothelial cell monolayers were treated with HBSS/ A, $250 \mathrm{U} / \mathrm{ml} \mathrm{TNF}$, or $0.1 \mu \mathrm{l} \mathrm{BRSV} / \mathrm{ml}$ for 3 or $6 \mathrm{~h}$, RNA was isolated and reversed transcribed, and E-selectin primers or GAPDH (not shown) primers were used for PCR amplification under the quantitative conditions as described in Methods. The PCR products were separated by agarose electrophoresis and visualized by ethidium bromide staining. The expected 1,200-bp product is the major product; GAPDH amplification demonstrated that equivalent amounts of RNA were carried through the process. Left three lanes, time zero monolayers; middle three lanes, 3-h treated monolayers; right three lanes, 6-h treated monolayers. $C$, control buffer-treated monolayers; $T$, TNF $\alpha$-treated monolayers; $B$, brown recluse spider venom-treated monolayers. $(B)$ Western blot of E-selectin immunoreactive material. Endothelial cells were

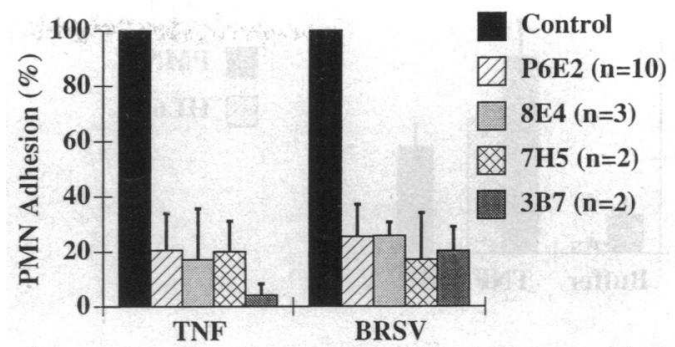

Figure 4. E-selectin monoclonal antibodies block PMN adhesion to Loxosceles venom-activated monolayers. Confluent monolayers were treated for $4 \mathrm{~h}$ with buffer, $250 \mathrm{U} / \mathrm{ml} \mathrm{TNF}$, or $0.1 \mu \mathrm{l} \mathrm{BRSV} / \mathrm{ml}$, the incubation medium was removed and the monolayer was washed with buffer, and then either HBSS/A or $10 \mu \mathrm{g} / \mathrm{ml}$ of the stated anti-E-selectin $\mathrm{mAb}$ was added. After $30 \mathrm{~min}$ at $37^{\circ} \mathrm{C}$, the antibody was removed, and either neutrophils alone (Control) or neutrophils containing $10 \mu \mathrm{g} / \mathrm{ml}$ of the antibody used to pretreat the monolayer to maintain its concentration during the coincubation were then added. Neutrophil adhesion after the 5-min coincubation was determined as described in Methods. Results from control incubations with an irrelevant antibody were not different from buffer-treated controls. Values shown are the mean and range of neutrophil adhesion in a single experiment; these results are typical of multiple experiments with the various antibodies $(n=2,21,3$, and 10 , respectively).

proadhesive surface from that induced by TNF $\alpha$. For instance, E-selectin recognizes a sialylated ligand on PMN and undifferentiated HL60 cells, and both of these cells adhere to cytokineactivated endothelial cells (25). We found that, while undifferentiated HL60 cells would bind to TNF $\alpha$-activated endothelial cells, they would not adhere to venom-activated endothelial cells (Fig. $5 \mathrm{~A}$ ). The simplest explanation for this is that these two cells express different ligands for E-selectin and that HL60 cells do not recognize E-selectin expressed by venom-treated endothelial cells. This conclusion is strengthened by the results in Fig. $5 \mathrm{~B}$. Here PMN were treated with low concentrations of chymotrypsin to remove PMN counterligands for adhesion molecules expressed by activated endothelial cells (29). We found that after exposure to very low levels $(0.01-0.1 \mathrm{U})$ of chymotrypsin binding of PMN to venom-activated monolayers was significantly reduced without a corresponding decrease in adhesion to TNF $\alpha$-treated monolayers. Higher concentrations of chymotrypsin (1 $\mathrm{U}$ ) reduced binding of PMN to cytokinetreated monolayers exactly as reported (29). A candidate PMN counterreceptor for E-selectin expressed by cytokine-activated monolayers is L-selectin (17), and anti-L-selectin antibodies block about half of leukocyte adhesion to cytokine-activated

treated with buffer, TNF $\alpha$, or $0.3 \mu \mathrm{l} / \mathrm{ml}$ Loxosceles venom for $4 \mathrm{~h}$. Cellular protein was solubilized with boiling SDS buffer, electrophoretically separated, and probed with the E-selectin antibody P6E2 in conjunction with enhanced chemiluminescence detection as described in Methods. Electrophoresed samples were either undiluted (1), one-fifth $(0.2)$, or one-tenth $(0.1)$ of the sample to estimate E-selectin abundance in TNF $\alpha$-treated endothelial cells. (C) FACS ${ }^{\circledR}$ analysis of endothelial cell E-selectin or ICAM-1 surface expression. Endothelial cells were treated with buffer, TNF $\alpha$, or $0.3 \mu \mathrm{l} / \mathrm{ml}$ Loxosceles venom for $4 \mathrm{~h}$, removed from their substrate, and stained with E-selectin monoclonal antibody (BBA7), ICAM-1 monoclonal antibody (18E3D), or control antibody. Staining of viable cells was determined as described in Methods. These experiments are typical of two other analyses. 


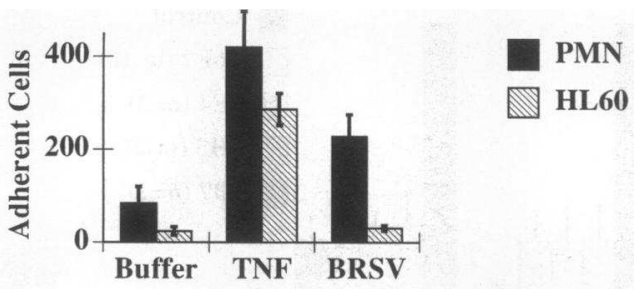

B

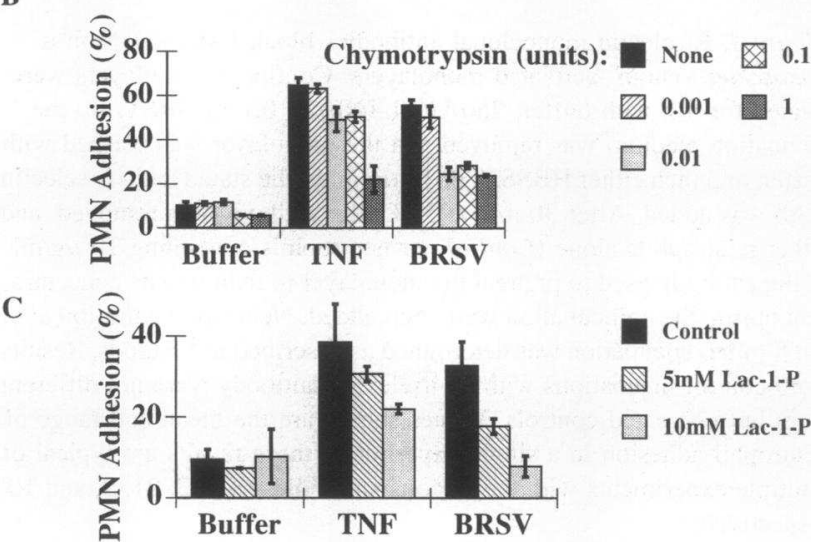

Figure 5. PMN adhesion to Loxosceles venom-activated endothelial cells differs from adhesion to TNF $\alpha$-activated monolayers. Endothelial cell monolayers were treated for $4 \mathrm{~h}$ with buffer, TNF $\alpha$, or $0.1 \mu \mathrm{l} \mathrm{BRSV/}$ $\mathrm{ml}$ as described in the legend to Fig. 1. (A) HL60 cells do not adhere to Loxosceles-activated monolayers. After the incubation, the monolayers were washed, and PMN and HL60 adhesion was determined by manually counting as described in Methods. Values shown represent the mean and deviation of adherent cells in six random fields and are representative of nine experiments. $(B)$ Low concentrations of chymotrypsin selectively reduce PMN binding to Loxosceles-activated monolayers. PMN were either untreated or treated with the stated concentration of chymotrypsin (given as chymotrypsin units per $10^{6} \mathrm{PMN}$ ) for 5 min, washed by low speed centrifugation, and resuspended in HBSS/ A. Adhesion to endothelial cell monolayers treated with $250 \mathrm{U} / \mathrm{ml}$ TNF or $0.1 \mu \mathrm{l} / \mathrm{ml}$ Loxosceles venom was as described in Methods, the data are typical of 13 experiments. $(C)$ Lactose-1-phosphate preferentially inhibits adhesion to Loxosceles venom-activated monolayers. PMN were incubated for $5 \mathrm{~min}$ with TNF- or Loxosceles venom-activated monolayers in the presence of the stated concentration of lactose-1phosphate before adhesion was quantified as described in Methods; data are typical of five experiments.

monolayers (33). In our experiments, the blocking anti-L-selectin mAb L1.4 (34) reduced PMN adhesion to cytokine-activated monolayers by $40 \%$, but blocked $<5 \%$ of the adhesion to venom-activated monolayers. PMN adhesion to venom-activated monolayers differs from adhesion to cytokine-activated ones in another way. We found (Fig. $5 C$ ) that lactose-1-phosphate, a sugar previously shown to block PMN and monocyte adhesion to cytokine-activated endothelial cells (16), was a much better inhibitor of PMN adhesion to venom-activated monolayers than to monolayers stimulated with TNF $\alpha$. This effect was limited to this sugar: lactose, mannose, or mannose-6-phosphate did not block adhesion to endothelial cells activated by either agonist (not shown). Thus, four independent approaches show that leukocyte recognition of venom-activated monolayers differs from recognition of $\mathrm{TNF} \alpha$-activated endothelium, even though E-selectin antibodies effectively inhibit adhesion induced by either agonist.

PMN bound to venom-activated monolayers do not change shape or migrate through the monolayer. We found several other unusual features of PMN adhesion to venom-activated endothelial cell monolayers. First, adhesion was visibly patchy and, at the microscopic level, adherent PMN formed chains that appeared like beads on a string (Fig. 6). This unusual pattern was caused by adhesion of the PMN almost exclusively over endothelial cell junctions (this was apparent when the focal plane was altered to visualize endothelial cells rather than the PMN bound to their surface). In contrast, PMN adhered diffusely over TNF $\alpha$-activated monolayers and then rapidly migrated to and through intracellular junctions. A second unusual characteristic of PMN adherent to venom-activated monolayers was that PMN bound to endothelial cell junctions did not change shape from spherical to the spread, polarized morphology that was apparent on cytokine-activated monolayers. Furthermore, these spherical PMN did not migrate below the monolayer and remained on the apical aspect of endothelial cell junctions for at least the $2 \mathrm{~h}$ during which we followed them. This result was quite different from the migration within minutes of PMN below cytokine-stimulated monolayers.

Venom-activated endothelial cells differentially express neutrophil agonists. Endothelial cell-dependent PMN adhesion results from both expression of a tethering molecule and a signaling molecule to induce functional responses from the bound PMN $(10,30)$. We considered the possibility that the lack of altered PMN morphology and migration below venom-treated endothelial cell monolayers was due to the expression of a tethering molecule in the absence of an appropriate neutrophil agonist. This seemed possible given the weak expression of $\mathrm{E}$ selectin described above. Accordingly, we determined if venomactivated endothelial cells synthesized and released IL-8, an early response gene product that is a potent mediator of neutrophil activation and extravasation (35-37). We collected supernatants of monolayers treated with $\mathrm{TNF} \alpha$ or Loxosceles venom and quantified IL- 8 by ELISA. We found that, in contrast to the weak induction of E-selectin, venom-exposed monolayers were significant producers of this cytokine: IL-8 production was stimulated 10 -fold by the venom, compared with a 22 -fold induction in response to TNF $\alpha$ (Fig. 7). Moreover, we found a second cytokine, GM-CSF, was induced by venom exposure, and unexpectedly that its accumulation by $4 \mathrm{~h}$ was far in excess of that expressed by TNF $\alpha$-exposed monolayers: Loxosceles venom induced a 6.4-fold increase in GM-CSF release compared with a $30 \%$ increase induced by TNF $\alpha$. This result was unexpected as stimulation of GM-CSF release is slow; elaboration in response to TNF $\alpha$ is detectable only by $8 \mathrm{~h}$ of exposure (38). Elaboration of this cytokine would also have functional consequences for adherent PMN since it is a direct PMN agonist (39-41) as well as a potent priming agent (42). In contrast to the elaboration of IL-8 and GM-CSF, venom stimulation of endothelial cell monolayers did not induce the synthesis and release of IL-6 (Fig. 7). Since monolayers treated with TNF $\alpha$ did show a major induction of IL-6 synthesis, this response clearly shows that venom-activated monolayers differentially express inflammatory gene products compared with this well established endothelial cell agonist. Expression of two cytokines that stimulate and/or prime PMN function also falsifies the postulate that venom-activated monolayers retain PMN on their apical surface due to an inability to appropriately activate them.

PMN bound to venom-activated monolayers degranulate. We determined if PMN bound to venom-activated monolayers had in fact been activated by agents elaborated by these monolayers. We examined intracellular free $\mathrm{Ca}^{2+}$ levels using INDO- 

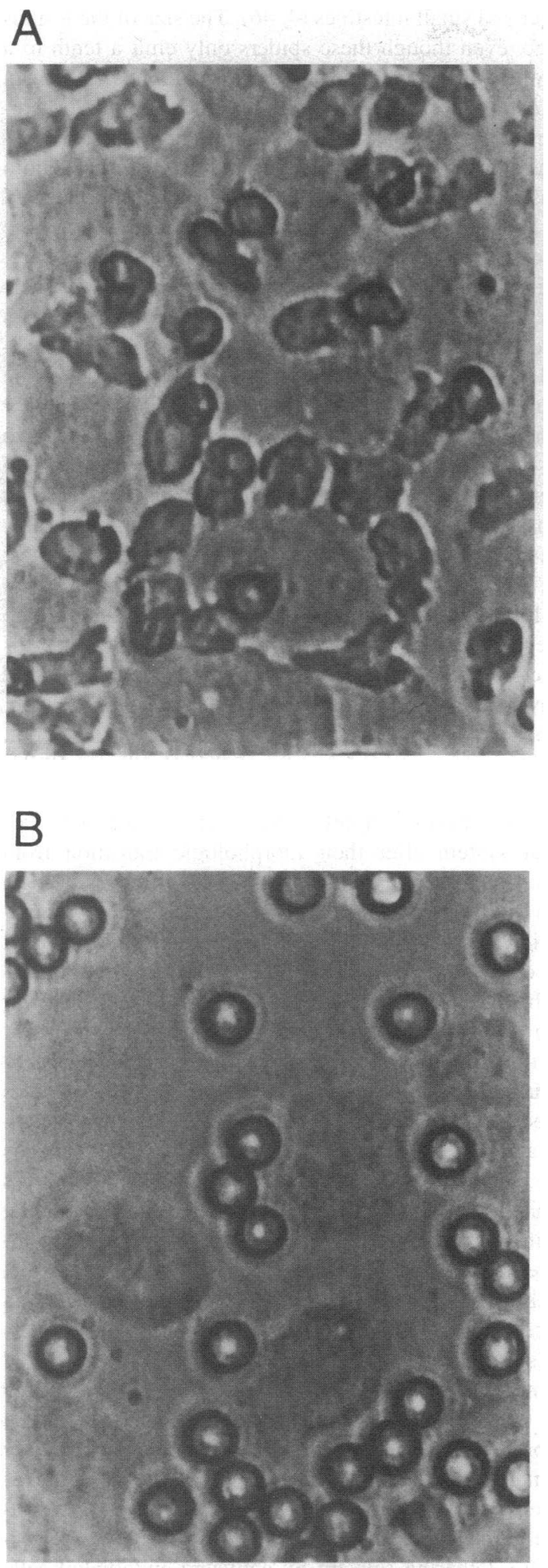

Figure 6. PMN bound to Loxosceles venom-activated endothelial cells do not change shape or transmigrate. HUVEC were treated for $4 \mathrm{~h}$ at $37^{\circ} \mathrm{C}$ with $(A) \mathrm{TNF} \alpha$ or $(B) 0.1 \mu \mathrm{l}$ Loxosceles venom $/ \mathrm{ml}$. After the incubation, the buffer was removed, the monolayers were washed, and neutrophils were added for the 5-min adhesion assay as described in Fig. 1. The monolayers were examined microscopically, and the image of bound neutrophils at the end of the 5-min adhesion assay was recorded on videotape. This recording was captured using NIH Image 1.47, and the image of the bound PMN was exported and photographed as described in Methods. The picture is from a randomly selected field and is typical of other fields and dozens of other experiments.

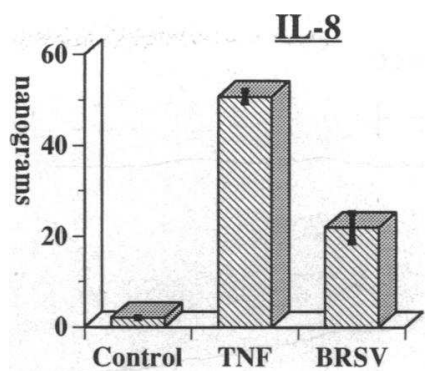

Figure 7. Loxosceles venom-activated endothelial cells release PMN agonists IL-8 and GMCSF, but not IL-6. HUVEC were treated for $4 \mathrm{~h}$ with HBSS/A, TNF $\alpha$, or $0.3 \mu \mathrm{l} / \mathrm{ml}$ of Loxosceles

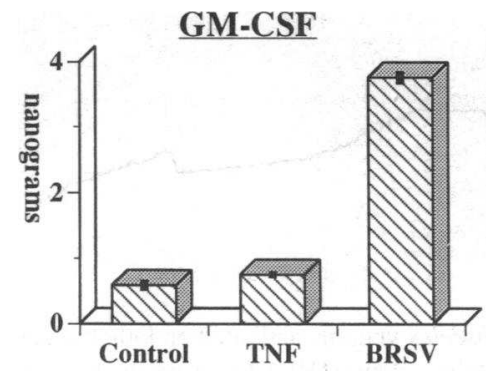
venom $/ \mathrm{ml}$. After the incubation, the buffer was removed, and the supernatants were assayed for IL-8, IL-6, or GM-CSF by sandwich ELISA as detailed in Methods. The endothelial cell monolayers were then used in the PMN adhesion assay described in Fig. 1 as a positive control: the increased amount of venom in these experiments produced the same level of PMN adhesion, determined in parallel, to venom- and TNF $\alpha$-activated monolayers. These results are representative of two other identical experiments.

1 to load the PMN and found that PMN contacting venomactivated endothelial cells, like those interacting with cytokinetreated monolayers, showed a distinct rise in intracellular $\mathrm{Ca}^{2+}$ levels (Fig. 8). The rise in intracellular free $\mathrm{Ca}^{2+}$ was rapid and occurred as soon as the neutrophils settled onto the monolayers. Thus, by this criterion, PMN adhering to venom-activated endothelial cells were activated. We next determined if the rise in intracellular $\mathrm{Ca}^{2+}$ in PMN adhering to venom-activated endothelial cells had a functional consequence. We looked for stimulated degranulation, an event that depends on a rise in intracellular $\mathrm{Ca}^{2+}$ (43) and found that contents from both primary and secondary granules were released from the adherent PMN (Fig. 9). Lactoferrin, a secondary (specific) granule marker, and elastase, a primary (azurophilic) granule marker, were present at levels equivalent to the amounts released from PMN adhering to TNF $\alpha$-activated monolayers. These results show that venomactivated endothelial cells stimulate bound PMN, causing them to degranulate, but these monolayers are either incapable of supporting PMN transmigration and/or they elaborate an inhibitor of transmigration.

Release of lytic enzymes from PMN, particularly those localized within the vascular lumen, might have adverse consequences after envenomation. Dapsone (a sulfone that dampens leukocyte responses) has been used as a therapy after Loxosceles envenomation (44) and is one of the few maneuvers aside from surgical excision of the lesion that may be successful. Therefore, 

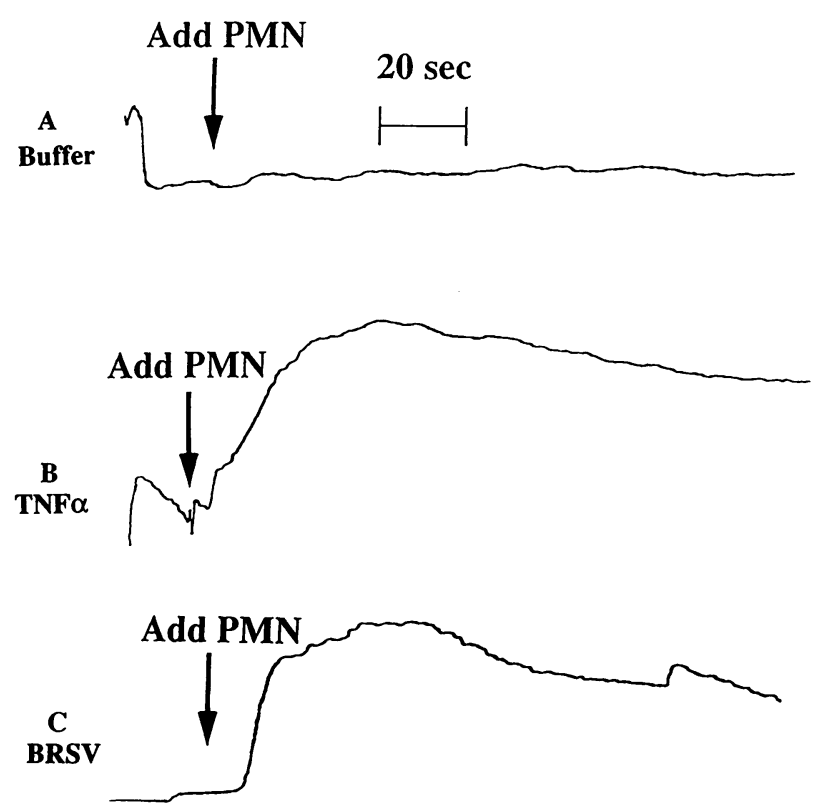

Figure 8. PMN bound to Loxosceles venom-activated endothelial cells exhibit an increase in intracellular calcium. HUVEC were treated for 4 h at $37^{\circ} \mathrm{C}$ with $(A) \mathrm{HBSS} / \mathrm{A},(B) 250 \mathrm{U} / \mathrm{ml} \mathrm{TNF} \alpha$, or $(C) 0.1 \mu \mathrm{l}$ Loxosceles venom $/ \mathrm{ml}$. After the incubation, the buffer was removed, the monolayers were washed, and INDO-1-labeled PMN were added at the time marked by the arrow. Increases in the ratio of fluorescence at 410 vs 480 during excitation at $380 \mathrm{~nm}$ was measured as described in Methods. These recordings are representative of three other experiments performed under the same conditions.

we examined the effect of this compound on degranulation after adhesion to venom-activated monolayers. We found no effect of dapsone, or other sulfones, on PMN adhesion to venomactivated endothelial cells (not shown). However, dapsone, over a range previously shown to reduce PMN-dependent endothelial cell cytotoxicity (45), reduced lactoferrin release by 20 and $80 \%$ at 10 and $100 \mu \mathrm{g} / \mathrm{ml}$, respectively. These observations suggest a molecular mechanism by which dapsone might mitigate the response to Loxosceles envenomation.

\section{Discussion}

Envenomation by the brown recluse spider can generate severe dermonecrotic lesions and may extend to hemorrhagic involve-

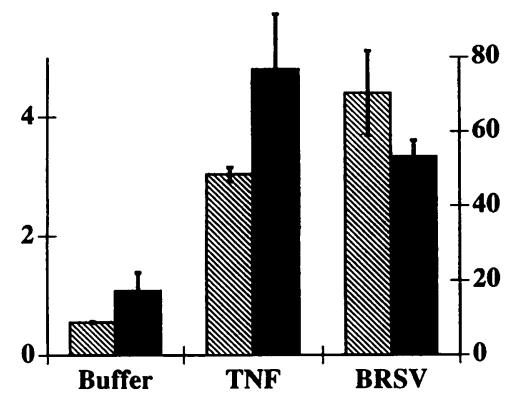

Figure 9. PMN bound to Loxosceles venom-activated endothelial cells release granular contents into the medium. Endothelial cells were treated with buffer, TNF, or Loxosceles venom as in Fig. 1. After this incubation, the monolayers were washed, and PMN were added and allowed to incubate with the endothe-

lium for $2 \mathrm{~h}$ at $37^{\circ} \mathrm{C}$. The supernatants were collected, and the amount of lactoferrin (hatched bars, $\mu \mathrm{g} / \mathrm{ml}$ ) from primary granules or elastase (black bars, $\mathrm{ng} / \mathrm{ml}$ ) released from secondary granules was determined by ELISA as described in Methods. Values shown represent the mean and range of duplicate points and are typical of five other experiments. ment of liver and small intestines $(4,46)$. The size of the lesions can be large, even though these spiders only emit a tenth to a half a microliter of venom upon stimulation (4). The mechanism by which Loxosceles venom induces necrotic lesions has remained elusive. It is clear that PMN depletion completely protects against the pathologic processes induced by the venom (5), demonstrating that the proximal event is inappropriate PMN activation. Paradoxically, PMN are not directly activated by the venom at relevant doses: the initiating event must lie elsewhere. Morphologic examination of tissues shows that leukocyte adherence to the capillary wall, the first observable change, occurs an hour after envenomation (Geren, C. R., unpublished observation). By $3 \mathrm{~h}$, endothelial cell damage becomes apparent at the ultrastructural level (8). These events suggest that the primary action of the toxin might be on the blood vessels (47). We have confirmed this possibility: the venom of Loxosceles reclusa activates endothelial cells. One measure of this activation is that venom-activated endothelial cells bind PMN and then provoke these cells to release the lytic contents of their granules. Unusually, these bound PMN fail to become polarized, a requirement for effective directed migration, and do not emigrate through the monolayer. This endothelial cell-dependent neutrophil stasis coupled with stimulated degranulation at the intimal surface may account for the untowards effects of envenomation.

PMN normally do not interact with the vascular wall but, in response to injury or a variety of endothelial cell- or PMNspecific agonists, they begin to roll along the vessel wall and some eventually become tightly bound. These then may exit the vascular system after their morphologic transition from round cells to migrating, polarized cells. Adhesion of PMN in response to direct agonists results from the functional upregulation of their CD11/CD18 integrins, which then bind to target molecules on endothelial cells. Adhesive interactions exclusively by this mechanism are likely to occur only where shear stress from flowing blood is reduced because the strength of this interaction, at least initially, is weak (11). In contrast, activation of the endothelium results in the expression of molecules that can mediate shear-resistant interactions. In response to rapidly acting agonists like thrombin or histamine, endothelial cells translocate P-selectin from intracellular Weibel-Palade bodies to their apical surface where it binds sialic acid-containing glycoproteins on unactivated PMN $(27,48)$. Alternatively, endothelial cells activated by TNF $\alpha$, IL-1, lipopolysaccharide, and, recently, IL-3 (49) synthesize E-selectin and express it on their surface where it binds a sialic acid-containing glycoprotein target(s) on PMN (50). The strength of selectin-mediated tethering interactions is sufficient to result in the initial rolling interaction $(51,52)$, but a signal to activate $\mathrm{PMN}$ is required for a complete inflammatory response. In the case of rapidly activated endothelial cells this is PAF (14), while in cytokineactivated cells it is soluble mediators like IL-8 $(35,37)$. Leukocyte extravasation and activation are therefore due to the expression of both a tethering selectin by activated endothelial cells and activation of the adhesive and migratory response of the juxtaposed PMN by an endothelial cell-derived agonist.

We found that as little as $10 \mathrm{nl}$ of venom induced unactivated PMN to adhere to endothelial cells previously exposed to the venom. The adhesion was dependent on the amount of venom and the time of exposure and was solely due to stimulation of the endothelial cells as the venom did not activate CD11/ CD18-dependent PMN adhesion when PMN were directly exposed to the venom. Adhesion of PMN to venom-activated endothelial cells in many ways resembled cytokine-stimulated 
endothelial cell-dependent adhesion. Venom exposure stimulated the synthesis and accumulation of E-selectin message, and this protein was expressed on the apical surface. This E-selectin was functional because we found that a panel of blocking monoclonal antibodies significantly inhibited PMN adhesion to venom-activated endothelial cells. Supporting evidence for a primary role for E-selectin in PMN adhesion to venom-activated endothelial cells is that adhesion developed over several hours and was dependent on de novo protein synthesis. We did not find a role for other adhesion molecules (P-selectin, L-selectin, ICAM-1, or $\beta 1$ and $\beta 2$ [CD18] integrins) in venom-induced adhesion. Thus, Loxosceles venom stimulates aspects of endothelial cell signal transduction that result in the induction of $\mathrm{E}$ selectin message synthesis and surface expression of E-selectin. These experiments also define a new endothelial cell agonist that induces responses previously only known to result from exposure to TNF $\alpha$, IL-1, endotoxin, and, now, IL-3.

Our data also show that PMN adhesion to venom-activated endothelial cells has unusual characteristics. For instance, undifferentiated HL60 cells failed to bind venom-induced monolayers. HL60 cells express sialylated Lewis x, a ligand for Eselectin, and this carbohydrate structure mediates HL60 cell adhesion to endothelial cells expressing E-selectin after cytokine stimulation (50). HL60 cells adhere to COS cells transfected with E-selectin (25) and they adhere to dishes coated with recombinant E-selectin chimeras $(53,54)$. Thus, in the literature and in our hands, HL60 cells adhere to E-selectin. It was therefore unexpected that this promyelocytic cell line would fail to adhere to venom-activated monolayers expressing Eselectin. However, in addition to binding to structures containing the sialylated Lewis $\mathrm{x}$ antigen (12), E-selectin recognizes other, undefined, counterreceptors $(54,55)$. Particularly relevant to our results is the observation $(54,56)$ that the density of $\mathrm{E}$ selectin affects ligand binding and selection. Our data show that surface expression of E-selectin after venom exposure is sparse: we find that $<10 \%$ of the amount of E-selectin expressed in response to TNF $\alpha$ is expressed after venom treatment. This low level of E-selectin expression may account for the unusual behavior of venom-activated monolayers towards PMN: the low level expression dictates that a different counterreceptor, potentially one that is less abundant but with a greater affinity, is recognized by this E-selectin than when it is more abundant. That a different counterreceptor is used by endothelial cells activated with the two agonists is readily apparent. We found differential sensitivity to lactose-1-phosphate, chymotrypsin pretreatment, and a complete inability to bind HL60 cells. Conversely, our data suggest that E-selectin is present in great excess, at least for the purposes of adhesion, on TNF $\alpha$-stimulated endothelial cells since the much lower amounts present on venom-treated cells can mediate the same level of neutrophil adhesion. Abundant expression of E-selectin may alter the ligand selection of some vascular endothelial cells and allow multivalent interaction with lower affinity neutrophil counterligands, but once a neutrophil enters an environment with less abundant E-selectin expression its behavior may more closely approximate the adhesive interactions with venom-activated cells than the maximally stimulated expression of cytokine-activated monolayers.

The limited amount of E-selectin on the surface of venomstimulated monolayers was presented in the context of basal levels of ICAM-1 surface expression, and an anti-ICAM-1 monoclonal antibody had no discernable effect on PMN adhesion to venom-treated monolayers. Although ICAM-1 and E- selectin can be independently regulated $(57,58)$, here there was little evidence of this. One caveat here is that basal expression of ICAM-1 would cloud our detection of small increases in ICAM-1 expression; however, we found another response that demonstrates that the venom does not completely mimic all of the actions of TNF $\alpha$. We found that, under conditions where similar levels of PMN adhesion were induced by venom and TNF $\alpha$, expression of IL- 6 was detectable only in supernatants derived from TNF $\alpha$-treated monolayers. Here, where control monolayers secrete no detectable IL-6, the responses to TNF $\alpha$ and Loxosceles venom are noticeably different. Differential stimulation of endothelial cell function is also apparent when E-selectin expression is compared with elaboration of IL-8. In contrast to its weak effects on expression of this adhesion molecule, we found that elaboration of $\mathrm{IL}-8$ in response to venom was nearly half that induced by TNF $\alpha$ after $4 \mathrm{~h}$ of exposure and about $60 \%$ of that induced by TNF $\alpha$ by $8 \mathrm{~h}$ (not shown). That this ratio was maintained over time shows that this truly represents differential induction rather than just an altered rate of expression. Unexpectedly, we found that venom also caused a large and early induction of GM-CSF release into the overlaying medium. Endothelial cells respond to IL-1 and TNF $\alpha$ with increased synthesis and release of $\operatorname{GM-CSF}(38,59,60)$, but production is a prolonged process: TNF $\alpha$-evoked bioactivity is just detectable at $8 \mathrm{~h}$ with increased levels after $24 \mathrm{~h} \mathrm{(38)}$; our ELISA failed to detect enhanced levels of GM-CSF by $4 \mathrm{~h}$ of TNF $\alpha$ stimulation. Our results show that the amount of immunoreactive GM-CSF released by $4-h$ venom stimulation is equivalent to that released by endothelial cells exposed to IL1 for $24 \mathrm{~h}$ (59): for this response, then, differential induction by these two agonists was a temporal one.

Cytokine induction of E-selectin, ICAM-1, IL-8, and GMCSF expression is complex and, at least for ICAM-1 (61) and GM-CSF (62), reflects both transcriptional and posttranscriptional regulation. The promoter regions of E-selectin, IL-8, IL-6 (63), and ICAM-1, but not GM-CSF, contain NF- $\kappa$ B recognition elements that are essential for enhanced transcription after cytokine stimulation. Of these, only for IL- 8 is the formation of an NF- $\kappa$ B complex necessary and (in conjunction with a constitutive c/EPB transcription factor) sufficient (64) for effective transcription: E-selectin (65-67), ICAM-1 $(61,68)$, and IL$6(69)$ require additional factors for efficient promoter activity. Additionally, regulation of E-selectin transcription may have an additional layer of complexity in that two different NF- $\kappa \mathrm{B}$ heterodimers bind the NF- $\kappa$ B recognition sequence (67). Eselectin expression is also modulated under some conditions by cAMP levels (70), but we found no evidence that increased levels of CAMP accounted for the differential expression of Eselectin between TNF $\alpha$ - and venom-treated monolayers: exposing venom-activated monolayers to $100 \mu \mathrm{M}$ Rp cAMP to inhibit cAMP-dependent kinase activity did not increase Eselectin expression of venom-treated monolayers (data not shown). Thus, a parsimonious explanation for our results is that venom leads to the release of NF- $\kappa$ B from its cytoplasmic inhibitory complex and its translocation to the nucleus where this single event induces IL-8 transcription. In support of this, we find by electrophoretic mobility shift assays that Loxosceles venom treatment, like TNF $\alpha$ exposure, results in the intranuclear appearance of $\kappa \mathrm{B}$ element binding factors that appropriately shift a $\kappa \mathrm{B}$ probe (not shown). The low production of $\mathrm{E}$ selectin, IL-6, and ICAM-1 suggests that other factors essential for efficient transcription of these genes are not produced upon venom exposure. The effect of venom on GM-CSF production 
is less obvious given the major effect of message stability on its production $(60,62)$ and that the identified regulatory element is a target for an unknown transcription factor. Independent control of GM-CSF and E-selectin transcription has been shown previously; an antisense oligonucleotide to the GM-CSF regulatory element blocks GM-CSF expression in IL-1-stimulated endothelial cells, but has no effect on E-selectin expression (59). We anticipate that the availability of an unusual agonist that differentially induces a panel of inflammatory cytokines and adhesive proteins will provide a new and valuable approach to define the intracellular signaling events in activated endothelial cells.

In addition to a differential induction of endothelial cell inflammatory responses, an intriguing difference between PMN interaction with venom- and cytokine-activated endothelial cells is the distribution of adherent PMN. Rather than occurring randomly over the apical surface of activated endothelial cells, PMN adhesion to venom-activated monolayers occurred just over endothelial cell junctions. We found, by video microscopy, that neutrophils contacting the monolayer slide or roll to the edge of an endothelial cell and then jostle one another to form a pattern that, at the microscopic level, appears as beads on a string. This pattern of adhesion probably does not result directly from the exclusive expression of E-selectin at the borders of venom-activated endothelial cells, as examination of unfixed monolayers by confocal microscopy showed that E-selectin was not just localized to cellular junctions (not shown). This suggests that other features of endothelial cell junctions are important in PMN-endothelial interactions. A junctional protein, such as CD31, may be involved in this, but we find (Martinez, M., S. M. Prescott, G. A. Zimmerman, and T. M. McIntyre, unpublished observations) that venom treatment disperses CD31 from its junctional location, giving rise to significant staining of the apical surface. Thus PECAM-1 is no longer correctly localized for such a role, and a direct experiment with the blocking monoclonal antibody hec7 (71) failed to alter the unusual pattern of junctional adhesion (not shown). It is intriguing that hec7 treatment of endothelial cells and PMN generates an unusual junctional adhesion pattern just like that of PMN adhering to venom-treated monolayers (71).

A second, and the most intriguing, difference in PMN response to venom-treated monolayers is that they did not become polarized, nor did they migrate beneath the monolayer. These PMN were spherical and remained at the apical aspect of endothelial cell junctions for at least the $2 \mathrm{~h}$ we extended these experiments. This is in contrast to the transmigration of over half the PMN in 5 min when quiescent PMN were exposed to cytokine-stimulated monolayers. We do not yet understand the basis for this unusual behavior, but we find that supernatants from venom-activated, but not TNF-exposed, monolayers inhibit PMN transmigration. This material is not the venom itself as even 10 times as much venom fails to inhibit integrin-mediated adhesion or degranulation (Feldhaus, M., S. M. Prescott, G. A. Zimmerman, and T. M. McIntyre, unpublished observations). We conclude that endothelial cells elaborate one or more inhibitors that selectively affect PMN shape change and chemotaxis. This is not due to the leukocyte adhesion inhibitor (LAI) effect of IL-8 (72) as adhesion (versus transmigration) was not adversely affected by venom supernatants containing IL-8; TNF $\alpha$-treated monolayers released twice as much IL- 8 as venom-treated ones; a 10-fold excess of a monoclonal antibody that blocks IL-8 activity failed to relieve the inhibition of transmigration through venom-treated monolayers (not shown).
Although PMN did not change shape or migrate beneath venom-activated monolayers, these endothelial cells did elaborate $\mathrm{PMN}$ agonist(s) capable of eliciting polarization and transmigration. IL-8 is a complete PMN agonist, while GM-CSF, in addition to its colony-forming activity, has potent effects on mature PMN. GM-CSF stimulates CD11/CD18-dependent PMN adhesion $(40,41)$, primes PMN degranulation in response to a second agonist (42), and stimulates release of secondary and tertiary granule markers from adherent $\operatorname{PMN}(39,40)$. Thus, venom-activated cells release a potent priming agent/agonist in addition to at least two direct PMN agonists. Correspondingly, we found that as PMN settled onto the monolayer their intracellular $\mathrm{Ca}^{2+}$ levels increased rapidly. Furthermore, we found that PMN adhering to venom-activated monolayers released their granular contents. We found both primary and secondary granule contents were released to the same extent from PMN adhering to venom- or cytokine-stimulated monolayers. Since these PMN had not been pretreated with cytochalasin B to enhance degranulation, it is possible that this level of degranulation could also occur in vivo. We conclude sequestration of PMN at sites of envenomation with inappropriate release of lytic enzymes in the vascular space may account for much of the tissue destruction that accompanies envenomation. Attenuation of degranulation of adherent neutrophils by dapsone may provide a rational basis for its use after envenomation.

We have identified a possible cellular and molecular basis for the PMN-dependent necrosis after envenomation by Loxosceles spiders. Prior work aimed at demonstrating a direct effect on PMN, or blood components, has not yielded a mechanism to account for the paradoxical requirement for the victim's PMN in the dermonecrosis that can follow envenomation. The potent effect of the venom on endothelial cells described here suggests that the inappropriate activation of PMN function by the venom is an indirect one. However, Loxosceles venom potently activates some, but not all, of the mechanisms that should result in the regulated extravasation of circulating PMN. The inappropriate accretion of PMN and their activation in the intravascular space suggest that this venom will be a useful tool to dissect the mechanisms that underlie normal leukocyte-endothelial cell interactions.

\section{Acknowledgments}

We thank the following people for the gifts of essential reagents: Drs. B. A. Wolitzky (Hoffmann-La Roche), C. W. Smith (Baylor College, Waco, TX), J. C. Paulson, L. E. Walker, and L. Phillips (Cytel) for blocking anti-E-selectin mAb; T. Tedder (Harvard University) for L1.4; S. D. Wright (The Rockefeller University) and P. Beatty (University of Utah) for IB4 and 60.3, respectively; R. Rothlein (Boehringer Ingelheim Ltd.) for RR1.4; S. Akiyama (National Institutes of Health) for mAb13; W. M. Gallitin (ICOS Corp.) for mAb 18E3D; Rodger McEver (Oklahoma Medical Research Foundation) for G1; W. A. Muller (The Rockefeller University) for hec7; and D. P. Jacobus (Jacobus Pharmaceutical Co., Princeton, NJ) for dapsone. We also thank Collis Geren (University of Arkansas) for many helpful discussions and reagents in the formative stages of this work. The PCR experiments performed by David A. Jones and the $\mathrm{Ca}^{2+}$ measurements by Ralph $\mathrm{E}$. Whatley are greatly appreciated. We thank Andrew S. Weyrich for aid with several ELISA assays; Jason Burks for his assistance with computer graphics; and Linda Jara for photography. We greatly appreciate the use of the FACS ${ }^{\circledR}$ analysis facility of Raymond Daynes. We thank the staff of the Labor and Delivery Service of the Latter Day Saints Hospital for invaluable help in acquiring umbilical veins; and Donelle Benson, Susan Cowely, and Margaret Vogel for their excellent technical assistance.

This work was supported by the Nora Eccles Treadwell Foundation 
and by the National Institutes of Health (grants HL-44525 and HL50153). Dr. Prescott and Dr. Zimmerman were Established Investigators of the American Heart Association during a portion of this work.

\section{References}

1. Atkins, J. A., C. W. Wingo, W. A. Sodeman, and J. E. Flynn. 1958. Necrotic arachnidism. Am. J. Trop. Med. Hyg. 7:165-184.

2. Wasserman, G. S., and P. C. Anderson. 1983. Loxoscelism and necrotic arachnidism. J. Toxicol. Clin. Toxicol. 21:451-472.

3. Rees, R. S., and D. S. Campbell. 1989. Spider bites. In Management of Wilderness and Environmental Emergencies. P. S. Auerbach and E. C. Geehr, editors. The C. V. Mosby Company, St. Louis. 543-548.

4. Smith, C. W., and D. W. Micks. 1968. A comparative study of the venom and other components of three species of Loxosceles. Am. J. Trop. Med. Hyg. 17:651-657.

5. Smith, C. W., and D. W. Micks. 1970. The role of polymorphonuclear leukocytes in the lesion caused by the venom of the brown spider. Lab. Invest. 22:90-93.

6. Babcock, J. L., D. J. Marmer, and R. W. Steele. 1986. Immunotoxicology of brown recluse spider (Loxosceles reclusa) venom. Toxicon. 24:783-790.

7. Majeski, J. A., J. D. Stinnett, J. W. Alexander, and G. G. Durst. 1977 Action of venom from the brown recluse spider (Loxosceles reclusa) on human neutrophils. Toxicon. 15:423-427.

8. Berger, R. S., E. H. Adelstein, and P. C. Anderson. 1973. Intravascular coagulation: the cause of necrotic arachnidism. J. Invest. Dermatol. 61:142-150.

9. Geren, C. R., L. N. Raymond, M. Edwards, and J. N. Beasley. 1987 Mechanism of action of the mammalian toxin from brown recluse spider venom. Fed. Proc. 46:2291a. (Abstr.)

10. Zimmerman, G. A., S. M. Prescott, and T. M. McIntyre. 1992. Endothelial cell interactions with granulocytes: tethering and signaling molecules. Immunol. Today 13:93-100.

11. Lawrence, M. B., C. W. Smith, S. G. Eskin, and L. V. McIntire. 1990 Effect of venous shear stress on CD18-mediated neutrophil adhesion to cultured endothelial cells. Blood. 75:227-237.

12. Bevilacqua, M. P., and R. M. Nelson. 1993. Selectins. J. Clin. Invest. 91:379-387

13. Zimmerman, G. A., T. M. McIntyre, and S. M. Prescott. 1985. Thrombin stimulates the adherence of neutrophils to human endothelial cells in vitro. $J$ Clin. Invest. 76:2235-2246.

14. Zimmerman, G. A., T. M. McIntyre, M. Mehra, and S. M. Prescott. 1990. Endothelial cell-associated platelet-activating factor: a novel mechanism for signaling intercellular adhesion. J. Cell Biol. 110:529-540.

15. Smiley, P. L., K. E. Stremler, S. M. Prescott, G. A. Zimmerman, and T. M. McIntyre. 1991. Oxidatively fragmented phosphatidylcholines activate human neutrophils through the receptor for platelet-activating factor. J. Biol. Chem. 266:11104-11110.

16. DiCorleto, P. E., and C. A. de la Motte. 1989. Role of cell surface carbohydrate moieties in monocytic cell adhesion to endothelium in vitro. $J$. Immunol. 143:3666-3672.

17. Picker, L. J., R. A. Warnock, A. R. Burns, C. M. Doerschuk, E. L. Berg, and E. C. Butcher. 1991. The neutrophil selectin LECAM-1 presents carbohydrate ligands to the vascular selectins ELAM-1 and GMP-140. Cell. 66:921-933.

18. Spertini, O., F. W. Luscinskas, G. S. Kansas, J. M. Munro, J. D. Griffin M. A. Gimbrone, and T. F. Tedder. 1991. Leukocyte adhesion molecule-1 (LAM1, L-selectin) interacts with an inducible endothelial cell ligand to support leukocyte adhesion. J. Immunol. 147:2565-2573.

19. Patel, K. D., G. A. Zimmerman, S. M. Prescott, and T. M. McIntyre. 1992. Novel leukocyte agonists are released by endothelial cells exposed to peroxide. $J$. Biol. Chem. 267:15168-15175.

20. Whatley, R. E., P. Nelson, G. A. Zimmerman, D. L. Stevens, C. J. Parker, T. M. McIntyre, and S. M. Prescott. 1989. The regulation of platelet-activating factor production in endothelial cells. J. Biol. Chem. 264:6325-6333.

21. Whatley, R. E., D. F. Fennell, J. A. Kurrus, G. A. Zimmerman, T. M McIntyre, and S. M. Prescott. 1990. Synthesis of platelet-activating factor by endothelial cells: the role of G proteins. J. Biol. Chem. 265:15550-15559.

22. Topham, M., S. M. Prescott, G. A. Zimmerman, and T. M. McIntyre. 1989. Neutrophil secretion while adherent to activated endothelium is differentially regulated. Clin. Res. 37:119a. (Abstr.).

23. Patel, K. D., G. A. Zimmerman, S. M. Prescott, R. P. McEver, and T. M. McIntyre. 1991. Oxygen radicals induce human endothelial cells to express GMP140 and bind neutrophils. J. Cell Biol. 112:749-759.

24. Funk, C. D., and G. A. FitzGerald. 1991. Eicosanoid forming enzyme mRNA in human tissues: analysis by quantitative polymerase chain reaction. $J$. Biol. Chem. 266:12508-12513.

25. Bevilacqua, M. P., S. Stengelin, M. A. Gimbrone, Jr., and B. Seed. 1989. Endothelial leukocyte adhesion molecule 1: an inducible receptor for neutrophils related to complement regulatory proteins and lectins. Science (Wash. DC). 243:1160-1165.

26. Luscinskas, F. W., M. I. Cybulsky, J. M. Kiely, C. S. Peckins, V. M
Davis, and M. A. Gimbrone. 1991. Cytokine-activated human endothelial monolayers support enhanced neutrophil transmigration via a mechanism involving both endothelial-leukocyte adhesion molecule-1 and intercellular adhesion molecule- 1 . J. Immunol. 146:1617-1625.

27. Varki, A. 1992. Selectins and other mammalian sialic acid-binding lectins. Curr. Opin. Cell Biol. 4:257-266.

28. Smith, C. W., T. K. Kishimoto, O. Abbass, B. Hughes, R. Rothlein, L. V. McIntire, E. Butcher, and D. C. Anderson. 1991. Chemotactic factors regulate lectin adhesion molecule 1 (LECAM-1)-dependent neutrophil adhesion to cytokine-stimulated endothelial cells in vitro. J. Clin. Invest. 87:609-618.

29. Jutila, M. A., T. K. Kishimoto, and M. Finken. 1991. Low-dose chymotrypsin treatment inhibits neutrophil migration into sites of inflammation in vivo: effects on Mac-1 and MEL-14 adhesion protein expression and function. Cell. Immunol. 132:201-214.

30. Lorant, D. E., K. D. Patel, T. M. McIntyre, R. P. McEver, S. M. Prescott, and G. A. Zimmerman. 1991. Coexpression of GMP-140 and PAF by endothelium stimulated by histamine or thrombin: a juxtacrine system for adhesion and activation of neutrophils. J. Cell Biol. 115:223-234.

31. Lorant, D. E., M. K. Topham, R. E. Whatley, R. P. McEver, T. M McIntyre, S. M. Prescott, and G. A. Zimmerman. 1993. Inflammatory roles of Pselectin. J. Clin. Invest. 92:559-570.

32. Erbe, D. V., B. A. Wolitzky, L. G. Presta, C. R. Norton, R. J. Ramos, D. K. Burns, J. M. Rumberger, B. N. N. Rao, C. Foxall, B. K. Brandley, and L. A. Lasky. 1992. Identification of an E-selectin region critical for carbohydrate recognition and cell adhesion. J. Cell Biol. 119:215-227.

33. Abbassi, O., C. L. Lane, S. Krater, T. K. Kishimoto, D. C. Anderson, L. V. McIntire, and C. W. Smith. 1991. Canine neutrophil margination mediated by lectin adhesion molecule-1 in vitro. J. Immunol. 147:2107-2115.

34. Spertini, O., G. S. Kansas, K. A. Reimann, C. R. Mackay, and T. F Tedder. 1991. Function and evolutionary conservation of distinct epitopes on the leukocyte adhesion molecule-1 (TQ-1, Leu-8) that regulate leukocyte migration. J. Immunol. 147:942-949.

35. Rot, A. 1992. Endothelial cell binding of NAP-1/IL-8: role in neutrophil emigration. Immunol. Today. 13:291-294.

36. Colditz, I. G., R. D. Zwahlen, and M. Baggiolini. 1990. Neutrophil accumulation and plasma leakage induced in vivo by neutrophil-activating peptide-1. J. Leukocyte Biol. 48:129-137.

37. Huber, A. R., S. L. Kunkel, R. F. Todd, and S. J. Weiss. 1991. Regulation of transendothelial neutrophil migration by endogenous interleukin-8. Science (Wash. DC). 254:99-102.

38. Broudy, V. C., K. Kaushansky, G. M. Segal, J. M. Harlan, and J. W Adamson. 1986. Tumor necrosis factor type $\alpha$ stimulates human endothelial cells to produce granulocyte/macrophage colony-stimulating factor. Proc. Natl. Acad. Sci. USA. 83:7467-7471.

39. Richter, J., T. Andersson, and I. Olsson. 1989. Effect of tumor necrosis factor and granulocyte/macrophage colony-stimulating factor in neutrophil degranulation. J. Immunol. 142:3199-3205.

40. Griffin, J. D., O. Spertini, T. J. Ernst, M. P. Belvin, H. B. Levine, Y. Kanakura, and T. F. Tedder. 1990. Granulocyte-macrophage colony-stimulating factor and other cytokines regulate surface expression of the leukocyte adhesion molecule-1 on human neutrophils, monocytes, and their precursors. J. Immunol. 145:576-584.

41. Gamble, J. R., T. H. Rand, A. F. Lopez, I. Clark-Lewis, and M. A. Vadas 1990. Heterogeneity of recombinant granulocyte-macrophage colony-stimulating factor-mediated enhancement of neutrophil adherence to endothelium. Exp. Hematol. (NY). 18:897-902.

42. Kaufman, S. E., J. F. DiPersio, and J. C. Gasson. 1989. Effects of human GM-CSF on neutrophil degranulation in vitro. Exp. Hematol. (NY). 17:800-804.

43. Sengelov, H., L. Kjeldsen, and N. Borregaard. 1993. Control of exocytosis in early neutrophil activation. J. Immunol. 150:1535-1543.

44. Rees, R. S., D. P. Altenbern, J. B. Lynch, and L. E. King. 1985. Brown recluse spider bites: a comparison of early surgical excision versus dapsone and delayed surgical excision. Ann. Surg. 202:659-663.

45. Martin, W. J., and D. L. Kachel. 1985. Reduction of neutrophil-mediated injury to pulmonary endothelial cells by dapsone. Am. Rev. Respir. Dis. 131:544547.

46. Babcock, J. L., R. L. Suber, C. H. Frith, and C. R. Green. 1981. Systemic effect in mice of venom apparatus extract and toxin from the brown recluse spider (Loxosceles reclusa). Toxicon. 19:463-471.

47. Jolly, R. D. 1965. The patholgenic action of the exotoxin of Corynebacte rium ovis. J. Comp. Pathol. 75:417-431.

48. Moore, K. L., N. L. Stults, S. Diaz, D. F. Smith, R. D. Cummings, A Varki, and R. P. McEver. 1992. Identification of a specific glycoprotein ligand for P-selectin (CD62) on myeloid cells. J. Cell Biol. 118:445-456.

49. Brizzi, M. F., G. Garbarino, P. R. Rossi, G. L. Pagliardi, C. Arduino, G. C. Avanzi, and L. Pegoraro. 1993. Interleukin 3 stimulates proliferation and triggers endothelial-leukocyte adhesion molecule 1 gene activation of human endothelial cells. J. Clin. Invest. 91:2887-2892.

50. Phillips, M. L., E. Nudelman, F. C. A. Gaeta, M. Perez, A. K. Singhal, S.-I. Hakomori, and J. C. Paulson. 1990. ELAM-1 mediates cell adhesion by 
recognition of a carbohydrate ligand, sialyl-le ${ }^{x}$. Science (Wash. DC). 250:11301135.

51. Ley, K., P. Gaehtgens, C. Fennie, M. S. Singer, L. A. Lasky, and S. D. Rosen. 1991. Lectin-like cell adhesion molecule 1 mediates leukocyte rolling in mesenteric venules in vivo. Blood. 77:2553-2555.

52. Lawrence, M. B., and T. A. Springer. 1991. Leukocytes roll on a selectin at physiologic flow rates: distinction from and prerequisite for adhesion through integrins. Cell. 65:859-873.

53. Lobb, R. R., G. Chi-Rosso, D. R. Leone, M. D. Rosa, S. Bixler, B. M Newman, S. Luhowskyj, C. D. Benjamin, I. G. Dougas, S. E. Goelz, C. Hession, and E. P. Chow. 1991. Expression and functional characterization of a soluble form of endothelial-leukocyte adhesion molecule 1. J. Immunol. 147:124-129.

54. Kojima, N., K. Handa, W. Newman, and S.-I. Hakomori. 1992. Multirecognition capability of E-selectin in a dynamic flow system, as evidenced by differential effects of sialidases and anticarbohydrate antibodies on selectin-mediated cell adhesion at low vs. high wall shear stress: a preliminary note. Biochem. Biophys. Res. Commun. 189:1686-1694.

55. Walchek, B., G. Watts, and M. A. Jutila. 1993. Bovine $\gamma / \delta$ T cells bind E-selectin via a novel glycoprotein receptor: first characterization of a lymphocyte/ E-selectin interaction in an animal model. J. Exp. Med. 178:853-863.

56. Larkin, M., T. J. Ahern, M. S. Stoll, M. Shaffer, D. Sako, J. O’Brien C.-T. Yuen, A. M. Lawson, R. A. Childs, K. M. Barone, et al. 1992. Spectrum of sialylated and nonsialylated fuco-oligosaccharides bound by the endothelialleukocyte adhesion molecule E-selectin. J. Biol. Chem. 267:13661-13668

57. Pober, J. S., M. R. Slowik, L. G. De Luca, and A. J. Ritchie. 1993 Elevated cyclic AMP inhibits endothelial cell synthesis and expression of TNFinduced endothelial leukocyte adhesion molecule-1, and vascular cell adhesion molecule-1, but not intercellular adhesion molecule-1. J. Immunol. 130:51145123.

58. Bradley, J. R., D. R. Johnson, and J. S. Pober. 1993. Endothelial activation by hydrogen peroxide. Am. J. Pathol. 142:1598-1609.

59. Segal, G. M., T. D. Smith, M. C. Heinrich, F. S. Ey, and G. C. Bagby, Jr. 1992. Specific repression of granulocyte-macrophage and granulocyte colonystimulating factor gene expression in interleukin-1-stimulated endothelial cells with antisense oligodeoxynucleotides. Blood. 80:609-616.

60. Kaushansky, K. 1989. Control of granulocyte-macrophage colony-stimulating factor production in normal endothelial cells by positive and negative regulatory elements. J. Immunol. 143:2525-2529.

61. Wertheimer, S. J., C. L. Myers, R. W. Wallace, and T. P. Parks. 1992.
Intercellular adhesion molecule-1 gene expression in human endothelial cells. $J$. Biol. Chem. 267:12030-12035.

62. Akahane, K., and D. H. Pluznik. 1993. Interferon- $\gamma$ destabilizes interleukin-1-induced granulocyte-macrophage colony-stimulating factor mRNA in murine vascular endothelial cells. Exp. Hematol. (NY). 21:878-884.

63. Libermann, T. A., and D. Baltimore. 1990. Activation of interleukin-6 gene expression through the NF- $\kappa \mathrm{B}$ transcription factor. Mol. Cell. Biol. 10:23272334

64. Mahe, Y., N. Mukaida, K. Kouji, M. Akiyama, N. Ikeda, K. Matsushima, and S. Murakami. 1991. Hepatitis B virus X protein transactivates human interleukin-8 gene through acting on nuclear factor $\kappa \mathrm{B}$ and CCAAT/enhancerbinding protein-like cis-elements. J. Biol. Chem. 266:13759-13763.

65. Montgomery, K. F., L. Osborn, C. Hession, R. Tizard, D. Goff, C. Vassallo, P. I. Tarr, K. Bomsztyk, R. Lobb, J. M. Harlan, and T. H. Pohlman. 1991 Activation of endothelial-leukocyte adhesion molecule 1 (ELAM-1) gene transcription. Proc. Natl. Acad. Sci. USA. 88:6523-6527.

66. van Huijsduijnen, R. H., J. Whelan, R. Pescini, M. Becker-Andre, A.-M Schenk, and J. F. DeLamarter. 1992. A T-cell enhancer cooperates with NF- $\kappa$ B to yield cytokine induction of E-selectin gene transcription in endothelial cells. J. Biol. Chem. 267:22385-22391.

67. van Huijsduijnen, R. H., R. Pescini, and J. F. DeLamarter. 1993. Two distinct NF- $\kappa \mathrm{B}$ complexes differing in their larger subunit bind the E-selectin promoter $\kappa \mathrm{B}$ element. Nucleic Acids Res. 21:3711-3717.

68. Voraberger, G., R. Schafer, and C. Stratowa. 1991. Cloning of the human gene for intercellular adhesion molecule 1 and analysis of its 5'-regulatory region. J. Immunol. 14:2777-2786.

69. Isshiki, H., S. Akira, O. Tanabe, T. Nakajima, T. Shimamoto, T. Hirano, and T. Kishimoto. 1990. Constitutive and interleukin-1 (IL-1)-inducible factors interact with the IL-1 responsive element in the IL-6 gene. Mol. Cell. Biol. 10:2757-2764.

70. Parhami, F., Z. T. Fang, A. M. Fogelman, A. Andalibi, M. C. Territo, and J. A. Berliner. 1993. Minimally modified low density lipoprotein-induced inflammatory responses in endothelial cells are mediated by cyclic adenosine monophosphate. J. Clin. Invest. 92:471-478.

71. Muller, W. A., S. A. Weigl, X. Deng, and D. M. Phillips. 1993. PECAM1 is required for transendothelial migration of leukocytes. J. Exp. Med. 178:449460.

72. Gimbrone, M. A., Jr., M. S. Obin, A. F. Brock, E. A. Luis, P. E. Hass, C. A. Hebert, Y. K. Yip, D. W. Leung, D. G. Lowe, W. J. Kohr, et al. 1989 Endothelial interleukin-8: a novel inhibitor of leukocyte-endothelial interactions. Science (Wash. DC). 246:1601-1603. 